\title{
Targeting Recovery from Acute Kidney Injury: Executive Summary from the Round Table Conference at the 19th International Conference on Continuous Renal Replacement Therapies (Manchester Grand Hyatt, San Diego, Calif., USA, March 2-3, 2014)
}

\author{
Ravindra L. Mehta ${ }^{a} \quad$ John A. Kellum ${ }^{b}$ \\ aDivision of Nephrology-Hypertension, Department of Medicine, University of California San Diego, San Diego, Calif., and \\ bThe Center for Critical Care Nephrology, CRISMA (Clinical Research, Investigation, and Systems Modeling of Acute Illness) Center, \\ Department of Critical Care Medicine, University of Pittsburgh School of Medicine, Pittsburgh, Pa., USA
}

\section{Contributions of These Proceedings}

1 Macedo E, Mehta RL: Targeting recovery from acute kidney injury: incidence and prevalence of recovery. Nephron Clin Pract 2014;127:4-9.

2 Vincent IS, Okusa MD: Biology of renal recovery: molecules, mechanisms, and pathways. Nephron Clin Pract 2014;127:10-14.

3 Abdel-Rahman EM, Okusa MD: Effects of aging on renal function and regenerative capacity. Nephron Clin Pract 2014;127:15-20.

4 Goldstein SL: Renal recovery at different ages. Nephron Clin Pract 2014;127:21-24.

5 Godin M, Macedo E, Mehta RL: Clinical determinants of renal recovery. Nephron Clin Pract 2014;127:25-29.

6 Heung M, Chawla LS: Acute kidney injury: gateway to chronic kidney disease. Nephron Clin Pract 2014;127:30-34.

7 Schneider AG, Bagshaw SM: Effects of renal replacement therapy on renal recovery after acute kidney injury. Nephron Clin Pract 2014;127:35-41.

8 Tran M, Parikh SM: Mitochondrial biogenesis in the acutely injured kidney. Nephron Clin Pract 2014;127:42-45.

9 Zager RA: Progression from acute kidney injury to chronic kidney disease: clinical and experimental insights and queries. Nephron Clin Pract 2014;127:46-50.

10 Martina MN, Noel S, Bandapalle S, Hamad ARA, Rabb H: T lymphocytes and acute kidney injury: update. Nephron Clin Pract 2014; 127:51-55.

11 He L, Livingston MJ, Dong Z: Autophagy in acute kidney injury and repair. Nephron Clin Pract 2014;127:56-60.

\section{KARGER}

E-Mail karger@karger.com

www.karger.com/nec
12 Bonventre JV: Maladaptive proximal tubule repair: cell cycle arrest. Nephron Clin Pract 2014;127:61-64.

13 Portilla D: Apoptosis, fibrosis and senescence. Nephron Clin Pract 2014;127:65-69.

14 Andringa KK, Agarwal A: Role of hypoxia-inducible factors in acute kidney injury. Nephron Clin Pract 2014;127:70-74.

15 Fleig SV, Humphreys BD: Rationale of mesenchymal stem cell therapy in kidney injury. Nephron Clin Pract 2014;127:75-80.

16 Kellum JA: How can we define recovery after acute kidney injury? Considerations from epidemiology and clinical trial design. Nephron Clin Pract 2014;127:81-88.

17 Billings FT IV, Shaw AD: Clinical trial endpoints in acute kidney injury. Nephron Clin Pract 2014;127:89-93.

18 Sharma A, Mucino MJ, Ronco C: Renal functional reserve and renal recovery after acute kidney injury. Nephron Clin Pract 2014;127: 94-100.

19 Endre ZH: Recovery from acute kidney injury: the role of biomarkers. Nephron Clin Pract 2014;127:101-105.

20 Hundae A, McCullough PA: Cardiac and renal fibrosis in chronic cardiorenal syndromes. Nephron Clin Pract 2014;127:106-112.

21 Liu KD: Therapeutic strategies for clinical trials targeting renal recovery. Nephron Clin Pract 2014;127:113-116.

The Conference was supported by NIH UAB-UCSD O'Brien Center grant P30 DK079337. 
Acute kidney injury (AKI) is increasingly recognized as a major contributor to adverse outcomes including the development of chronic kidney disease (CKD). Several studies have demonstrated that lack of recovery from AKI is associated with worse outcomes, including higher mortality, reduced functional status and increased resource utilization. Recent evidence suggests that the duration of AKI is an important factor determining outcome in addition to the underlying severity of injury. Consequently, there is a major imperative to focus our efforts on enhancing renal recovery as early as possible to ensure a complete return of renal function to ultimately improve outcomes from AKI. However, there are several gaps in our knowledge of the pathophysiology and clinical course following AKI that contribute to non-recovery. This round table conference was designed to review our current understanding of the underlying biology and epidemiology of recovery following AKI to identify targets for intervention and define the best diagnostic and therapeutic strategies to enhance complete recovery after AKI. The conference convened international experts representing basic, translational and clinical researchers in AKI who focused on three broad themes: the epidemiology and clinical determinants of renal recovery; the biology of renal recovery, and strategies to identify, track and target recovery. Each participant was asked to prepare a summary of their assigned topic reflecting the discussion. These are presented as a compilation in this issue of Nephron Clinical Practice. We have summarized the key areas that were discussed below.

A key issue that was discussed was the variation in definitions for renal recovery in the literature that have made it challenging to establish the epidemiology of renal recovery. While the definition of AKI has undergone standardization over the last decade, beginning with RIFLE [1] and most recently with the KDIGO clinical practice guideline [2], there is no real consensus around what is meant by recovery. In most instances, recovery has been linked to the severity of AKI and evaluated as a continued need for renal replacement therapy or an improvement in renal function to within a particular range (e.g. 20\%) of the initial renal function prior to AKI. Unfortunately, defining a reference point for comparison is not always feasible since a significant number of patients with AKI are first seen without any prior knowledge of their level of renal function. A related challenge for defining recovery comes from the competing endpoint of death. It has been long recognized that patients with CKD are more likely to die than progress to end-stage renal disease [3]. The same relationship is apparent after severe AKI, where many more patients who survive initial hospitalization will be dead at 60 days than on dialysis [4]. This relationship is complicated further by the age of the patient younger patients are more likely to survive long enough to suffer the long-term complications following AKI. As such, creating robust definitions for AKI recovery is both critical and challenging. The outcomes following AKI include both renal (CKD and end-stage renal disease), nonrenal outcomes (e.g. cardiovascular events) and mortality. Renal outcomes are subject to various forms of bias. For example, dialysis use may be subject to some degree of clinician judgment and patient preferences may also impact the endpoint. Creatinine too has an imperfect relationship to renal function, especially at higher glomerular filtration rate (GFR), and may be impacted by changing muscle mass - common in critically ill patients. Thus, real and 'real-time' measures of GFR might be better suited to monitor these patients. In addition, creatinine and GFR might return to normal and yet there may be a loss of renal functional reserve (the ability to increase GFR in response to a protein load). Efforts to quantify this defect may also be important in the context of assessing recovery. Despite these limitations, several clinical factors, including the severity, duration and frequency of kidney injury, have been associated with a lack of recovery and represent measurable factors for developing clinical prognostic models.

Given the complexity and uncertainty in defining recovery after AKI, there is significant difficulty in determining the risk factors and underlying mechanisms for failure to recover. Advanced age is a strong predisposing factor for non-recovery, and various mechanisms from telomere shorting to cyclin-dependent cell senescence have been described to explain this relationship. However, there is also complexity and controversy surrounding the effect of aging on susceptibility to fibrosis $[5,6]$. While several biological pathways, including mitochondrial dysfunction [7], hypoxia [8], apoptosis [9], autophagy [10] and immune modulation [11], have been identified in experimental models, further research is needed to evaluate the interplay of these different mechanisms. The role of resident stem cells in kidney repair and the differences in injury models in contributing to repair versus progression continue to be areas of intense research.

A framework for assessing renal recovery was proposed to encompass conceptsof renal functional reserve, inception, timing and magnitude of renal functional return. These measurements can be further enhanced by incorporation of novel biomarkers of kidney damage and repair. The inclusion of renal functional recovery as an 
independent endpoint or in combination with other endpoints, such as death, dialysis or persistent renal dysfunction (e.g. 25-50\% reduction in GFR), to build a composite endpoint termed major adverse kidney events was discussed [12]. The occurrence of major adverse kidney events at 30,60 or 90 days are outcomes that are clear and relatively easy to obtain for clinical trials. Events at 90 days are preferred since early endpoints may still be unstable. Further studies will be necessary to validate these concepts. Several molecules targeting specific pathways identified for injury, repair and progression are in various stages of development, and early clinical trials and their results will serve to advance this field.

In summary, this round table conference highlights an emerging area for focused attention. Based on the discussion, it is evident that there is a great need for further improving our knowledge of the underlying mechanisms, course and outcomes of recovery following AKI, as well as for developing tools for assessing likelihood of renal recovery, differentiating recovery from progression and identifying therapeutic targets for enhancing recovery from AKI. We anticipate that the discussion from this conference will provide a framework for future endeavors in this area and a means to improve our patient's lives.

\section{Acknowledgment}

The work was supported by NIH UAB-UCSD O'Brien Center grant P30 DK079337.

\section{Disclosure Statement}

This round table conference was funded in part by generous support in form of unrestricted educational grants from Abbvie Inc.; Alere Medical, Astute Medical Inc., Cardiorentis, Gambro Inc. and Keryx. The sponsors had no input on the content of this paper.

\section{References}

1 Bellomo R, Ronco C, Kellum JA, Mehta RL, Palevsky P: Acute renal failure - definition, outcome measures, animal models, fluid therapy and information technology needs: the Second International Consensus Conference of the Acute Dialysis Quality Initiative (ADQI) Group. Crit Care 2004;8:R204-R212.

2 Kidney Disease: Improving Global Outcomes (KDIGO) Acute Kidney Injury Work Group: KDIGO clinical practice guideline for acute kidney injury. Kidney Int Suppl 2012;2:1141.

- 3 Lo LJ, Go AS, Chertow GM, McCulloch CE, Fan D, Ordonez JD, Hsu CY: Dialysis-requiring acute renal failure increases the risk of progressive chronic kidney disease. Kidney Int 2009;76:893-899.

-4 Palevsky PM, Zhang JH, O'Connor TZ, Chertow GM, Crowley ST, Choudhury D, Finkel K, Kellum JA, Paganini E, Schein RM, Smith MW, Swanson KM, Thompson BT, Vijayan A, Watnick S, Star RA, Peduzzi P: Intensity of renal support in critically ill patients with acute kidney injury. N Engl J Med 2008;359: $7-20$.
5 Clements ME, Chaber CJ, Ledbetter SR, Zuk A: Increased cellular senescence and vascular rarefaction exacerbate the progression of kidney fibrosis in aged mice following transient ischemic injury. PLoS One 2013;8:e70464.

-6 Chkhotua A, Shapira Z, Tovar A, Shabtai E, Yussim A: Cellular senescence: a new marker of kidney function recovery after ischemic injury in rats. Transplant Proc 2001;33:29102915.

-7 Hall AM, Rhodes GJ, Sandoval RM, Corridon $\mathrm{PR}$, Molitoris BA: In vivo multiphoton imaging of mitochondrial structure and function during acute kidney injury. Kidney Int 2013; 83:72-83.

-8 Singh P, Ricksten SE, Bragadottir G, Redfors B, Nordquist L: Renal oxygenation and haemodynamics in acute kidney injury and chronic kidney disease. Clin Exp Pharmacol Physiol 2013;40:138-147.
9 Sutton TA, Hato T, Mai E, Yoshimoto M, Kuehl S, Anderson M, Mang H, Plotkin Z, Chan RJ, Dagher PC: p53 is renoprotective after ischemic kidney injury by reducing inflammation. J Am Soc Nephrol 2013;24:113124

10 Isaka Y, Kimura T, Takabatake Y: The protective role of autophagy against aging and acute ischemic injury in kidney proximal tubular cells. Autophagy 2011;7:1085-1087.

11 Pino CJ, Yevzlin AS, Lee K, Westover AJ, Smith PL, Buffington DA, Humes HD: Cellbased approaches for the treatment of systemic inflammation. Nephrol Dial Transplant 2013;28:296-302.

12 Chawla LS, Amdur RL, Shaw AD, Faselis C, Palant CE, Kimmel PL: Association between $\mathrm{AKI}$ and long-term renal and cardiovascular outcomes in United States Veterans. Clin J Am Soc Nephrol 2014;9:448-456. 